\title{
Künt travma sonrası göz içi lensin subkonjonktival dislokasyonu; psödofakosel
}

\section{Subconjunctival dislocation of intraocular lens after blunt trauma; pseudophacocel}

\author{
Hüseyin Mayalı ${ }^{1}$ Sema Malgaz ${ }^{1}$ Secep Göktuğ Seymenoğlu ${ }^{2}$ Re Emin Kurt Re $^{1}$ \\ ${ }^{1}$ Celal Bayar Üniversitesi Tıp Fakültesi, Göz Hastalıkları Anabilim Dalı, Manisa, Türkiye \\ ${ }^{2}$ Özel Karşıyaka Göz Hastanesi, Göz Hastalıkları Kliniği, İzmir, Türkiye
}

\section{Öz}

72 yaşında kadın hasta sol gözde kızarıklık ve şişlik nedeniyle kliniğimize başvurdu. Hastanın öyküsünde yaklaşık 1 ay önce araç dışı trafik kazası geçirdiği öğrenildi. Düzeltilmiş en iyi görme keskinliği sol gözde el hareketi düzeyinde idi. Biyomikroskobik muayenede hifema, skleral perforasyon hattı ve göz içi lensin üst subkonjonktival alanda olduğu görüldü. Hastanın intravitreal hemorajisinin olması nedeniyle hastaya sol pars plana vitrektomi ve göz içi lensinin subkonjonktival alandan çıkarılması ameliyatı yapıldı. Olgumuz başka bir operasyon istemediğinden afak olarak takip edildi. Pseudofakik hastalarda oküler künt travmalar sonrası göz içi lensinin konjonktiva altına yer değiştirebileceği akılda tutulmalıdır.

Anahtar Sözcükler: Göz yaralanmaları, göz içi lensler.

\begin{abstract}
A 72-year-old woman presented with redness and swelling in the left eye. She had a traffic accident one month ago. Her best-corrected visual acuity was hand movement level in the left eye. Slit-lamp examination revealed hyphemia, scleral perforation and subconjunctival dislocation of intraocular lens. Pars plana vitrectomy was performed for hyphemia and intraocular lens extracted from subconjunctival area. Patient didn't want seconder intraocular lens implantation and followed as aphakic. As a result, in patients with pseudophakia, intraocular lens may replace under conjunctiva after blunt traumas to the eye.
\end{abstract}

Keywords: Eye Injuries, intraocular lenses.

\section{Giriş}

Oküler cerrahi geçirmiş gözlerde travma sonrası eski korneal kesi alanlarından rüptürler ile sıklıkla karşılaşılabilmektedir. Psödofakik gözde geçirilen travma, göz içi lensin (GIL) dislokasyonuna neden olabilmekte, ciddi ve acil müdahale gerektiren komplikasyonlara yol açabilmektedir. Travma ile GiL suprakoroidal boşluk (1), vitreus (2), ön kamara, subkonjonktival alan (3-5) veya göz küresinin dışına çıkabilir. Gíl'nin

Yazışma Adresi: Hüseyin Mayalı

Manisa Celal Bayar Üniversitesi Tıp Fakültesi, Göz Hastalıkları Anabilim Dalı, Manisa, Türkiye

E-mail:drmayali@hotmail.com

Makalenin Geliş Tarihi: 21.11.2018 Kabul Tarihi: 05.02.2019 subkonjonktival dislokasyonu psödofakosel olarak da adlandırılır. Nadir görülen bu durum tüm dislokasyonların \%13'ünden azını oluşturmaktadır. Gín'nin subkonjonktival dislokasyonu ilk olarak 1977 'de Biedner ve ark. tarafından tanımlanmıştır (6). $\mathrm{Bu}$ olgu sunumunda travma sonrası üst subkonjonktival alana GiL dislokasyonu saptanan olguyu sunmayı amaçladık. Bu yazı için hastadan tıbbi verilerinin yayınlanabileceğine ilişkin yazılı onam belgesi alındı. 


\section{Olgu sunumu}

Yetmiş iki yaşında kadın hasta yaklaşık bir ay önce araç dışı trafik kazası sonrası gelişen sol gözde şişlik ve kızarıklık şikâyeti ile başvurdu. Hastanın bilateral katarakt operasyonu öyküsü mevcut olup glokom tanısı ile takipli olduğu öğrenildi. Hastanın sol gözde görme keskinliği el hareketi düzeyinde idi.

Biyomikroskobik ön segment muayenesinde sol gözde saat 12 hizasında limbustan nazale ve arkaya uzanan skleral perforasyon hattı, irisi defektif, kapsül önünde koagülüm, ön kamarada yaklaşık 2 mm'lik hifema, pupil önünde fibrinoid reaksiyon izlendi, GíL görülmedi. Sol gözün biyomikroskobik konjonktiva muayenesinde üst bulbar konjunktiva altında GíL izlendi (Şekil-1).

Göz dibi görülemedi. Orbital bilgisayarlı tomografide yabancı cisim izlenmedi. Ultrasonografik görüntülemede vitreus hemorajisi izlendi. Hastaya genel anestezi altında skleral rüptür tamiri, subkonjonktival GíL çıkarılması, pars plana vitrektomi planlandı. Cerrahi sırasında retinada saat $10-12$ arası uzanan retinal yırtık saptandı ve endolazer ile kriyoterapi uygulandı. Ameliyat sonrası altıncı ay takibinde düzeltilmiş en iyi görme keskinliği $1 / 10$ seviyesindeydi. $(+14,50 ;-8.00$; 110). Olgu başka bir operasyon istemediğinden afak olarak takip edildi.

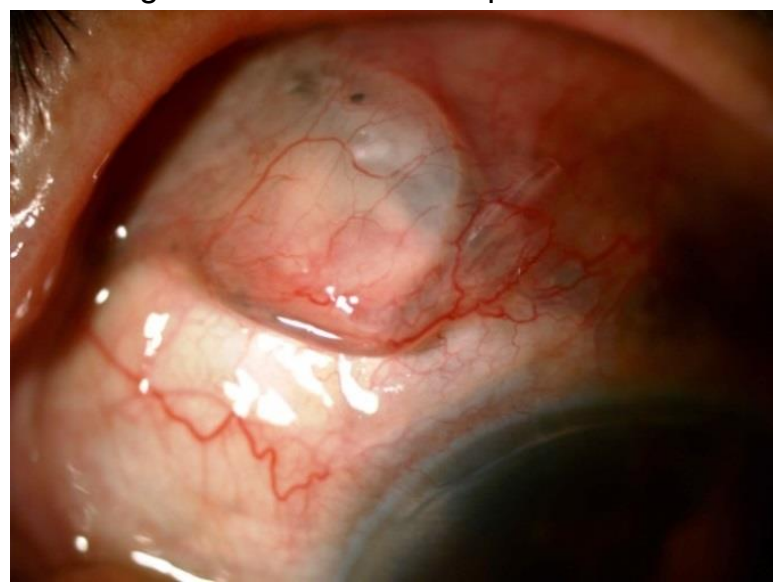

Resim-1. Üst bulbar konjonktiva altına GíL dislokasyonu görülüyor.

\section{Tartışma}

Oküler travmalar sık karşılaşılan ve komplikasyonları nedeniyle görmenin ve gözün kaybına, bununla birlikte ekonomik sorunlara yol açan bir sağlık sorunudur ve bu yüzden tanı, tedavi ve takipleri büyük önem taşımaktadır. Oküler travma sonrası GíL'nin subkonjonktival dislokasyonu nadir bir komplikasyondur. Travma sonrası dislokasyona neden olan birçok faktör arasında; ileri yaş, romatoid artrit, sklerit veya bağ dokuyu etkileyen bozukluklar, travmanın şiddeti, implant süresi, GíL yerleşimi, özellikle ekstrakapsüler katarakt ekstraksiyonu gibi geniş insizyonlar içeren cerrahi girişimler sayılabilir. Arka yerleşimli GíL'nin ön kamara yerleşimli Gíl'ne göre subkonjonktival alana dislokasyonu daha nadir görülmektedir. Künt travma sonrası GíL'nin subkonjonktival alana dislokasyonu gençlere nazaran yaşlılarda skleral elastisitenin azalmasına bağlı olarak daha sık karşılaşılmaktadır (8).

Oküler travmalar çoğunlukla temporal bölgeye olmakta, oküler rüptür de darbenin neden olduğu enerji yansıtması nedeniyle üst nazalde daha fazla görülmektedir. Literatürde sadece Mohan ve ark. künt travma sonrası arka kamara GiL' nin alt subkonjonktival alana dislokasyonunu bildirmişlerdir (9). Bizim olgumuzda da rüptür üst nazaldeydi ve arka kamara GiL dislokasyonu üst nazal subkonjonktival alanda izlendi.

GíL dislokasyonu tanısında dikkatli bir klinik muayene yeterli olsa da, görüntüleme teknikleri, ilişkili sklera rüptürünün yerinin doğru belirlenmesi için kullanılabilir. Bunun için ultrasonik biyomikroskobi (UBM), ön segment optik koherens tomografi ve B-taramalı ultrasonografi (USG) tercih edilebilir $(1,4,6)$. Btarama USG ve UBM, enfeksiyon ve göz içi içeriği ekstraksiyonu riski nedeniyle açık glob hasarında nispeten kontrendikedir. GíL dislokasyonu önünde iris dokusu bulunması veya yoğun subkonjonktival kanamanın olması, biyomikroskopik geniş/diffüz aydınlatma ile teşhisin konmasını zorlaştırabilir. Bizim olgumuzda subkonjonktival hemoraji ve önünde doku bulunmuyordu. Bunlar tanıyı koymamızda kolaylaştırıcı faktörler idi. Travma, psödofakoselin en sık görülen nedeni olup, sıklıkla hifema veya vitreus kanamaları ile birliktedir. Bu nedenle tanıda oftalmoskopi yararlı olmayabilir (4). Bizim vakamıda hifema ve intravitreal hemoraji nedeniyle fundus oftalmoskopik olarak değerlendirilmedi. Oküler USG'de vitreus hemorajisi saptandı.

\section{Sonuç}

Travma sonrası Gil'nin subkonjonktival dislokasyonu nispeten nadir olmasına rağmen karşılaşılabilen bir durumdur. Daha önceden psödofakik olduğu bilinen veya öğrenilen travmatik hastalarda GíL'i görülemiyorsa, konjonktiva altına yer değiştirebileceği akılda tutulmalı ve detaylı konjonktival tarama yapılmalıdır. 


\section{Kaynaklar}

1. Foster JA, Lam S, Joondeph BC, Sugar J. Suprachoroidal dislocation of a posterior chamber intraocular lens. Am J Ophthalmol 1990; 109 (6): 731-2.

2. Assia El, Blotnick CA, Powers TP, Legler UF, Apple DJ. Clinicopathologic study of ocular trauma in eyes with intraocular lenses. Am J Ophthalmol 1994; 117 (1): 30-6.

3. Bene C, Kranias G. Subconjunctival dislocation of a posterior chamber intraocular lens. Am J Ophthalmol 1985; 99 (1): 85-6.

4. Mandal AK, Anand R. Traumatic pseudophacocele. Indian J Ophthalmol 2003; 51 (2): 177-8.

5. Chandravanshi SL, Dwivedi A, Tirkey ER, Choudhary P. Golden half ring sign for identification of pseudophacocele. Indian J Ophthalmol 2015; 63 (3): 259-61.

6. Biedner B, Rothkoff L, Blumenthal M. Subconjunctival dislocation of intraocular lens implant. Am J Ophthalmol 1977; 84 (2): 265-6.

7. Kumar A, Nainiwal SK, Dada T, Ray M. Subconjunctival dislocation of an anterior chamber intraocular lens. Ophthalmic Surg Lasers 2002; 33 (4): 319-20.

8. Bhattacharjee K, Bhattacharjee H, Deka A, Bhattacharyya P. Traumatic phacocele: Review of eight cases Indian J Ophthalmol. 2007; 55 (6): 466-8.

9. Mohan A, Kaur N, Sharma V. Inferior subconjunctival dislocation of posterior chamber intraocular lens after blunt trauma Indian J Ophthalmol. 2017; 65 (6): 521-3. 